\title{
Breath Actuated Nebulizer
}

National Cancer Institute

\section{Source}

National Cancer Institute. Breath Actuated Nebulizer. NCI Thesaurus. Code C143007.

A nebulizer that creates an aerosol in response to the patient's inspiratory flow. 